\title{
The (im)possibilities of dialogue across feminism and childhood scholarship and activism
}

Katherine Twamley*, Rachel Rosen, and Berry Mayall

* Corresponding author

Institutional address (same for all): Social Science Research Unit, UCL Institute of Education, 18 Woburn Square, London WC1H 0NR

Email addresses: katherine.twamley@ucl.ac.uk; r.rosen@ucl.ac.uk; b.mayall@ucl.ac.uk

\begin{abstract}
The relations between those positioned as women and as children, and the political and intellectual consequences of how we conceptualise these connections, has received only scant attention. In this article we describe a symposium and on-going project which aim to bring together community-based and academic scholars to debate the intersections and perceived antagonisms between various forms of feminism and the politics of childhood. We trace how these intersections have been debated in the literature and outline the potential benefits and pitfalls of encouraging further connections between these fields. Drawing on our symposium experience, we also outline the challenges involved in bringing together academic and community-based scholars and activists, and consider the implications for similar future endeavours.
\end{abstract}

Keywords: Feminism; gender; women; children; generation; childhood studies; activism; knowledge production

This work was supported by UCL Grand Challenges. 


\section{The (im)possibilities of dialogue across feminism and childhood scholarship and activism}

It has been almost fifty years since Shulamith Firestone (1971, p.118) declared: 'We must include the oppression of children in any program for feminist revolution." Yet, as Ohad Zehavi argued at the symposium 'Feminism and the Politics of Childhood: Friends or foes?', Firestone's powerful invocation has been little more than a footnote in the history of feminist and childhood scholarship and activism. The relations between those positioned as women and as children, and the political and intellectual consequences of how we conceptualise these connections, has received only scant attention, a gap that this symposium, organised by the authors, sought to address.

The symposium was held at University College London (UCL) on $16^{\text {th }}$ and $17^{\text {th }}$ November 2015, bringing together 30 activists and (mostly) academic scholars to unpack the intersections and perceived antagonisms between various forms of feminism and the politics of childhood. We will trace how our ideas for this project emerged and the development of the symposium, and consider some of the challenges involved in efforts to cross the boundaries of disciplines, critical perspectives, and academic and public lives.

\section{The emergence of a project on feminism and childhood}

A conflux of scholarly, political and institutional factors led us to this project on feminism and the politics of childhood. Two of our members have been interested in questions about the relations between women and children for some time. Berry Mayall (2002) has written about the emergence of the sociology of childhood with its emphasis on the socio-political character of childhood and on children as a social group, and on the tense, but often parallel, trajectory with feminist scholarship. Rachel Rosen's work has been concerned with the ways in which women and children are connected, often in apparently antagonistic ways, in social movements and community-based activism (e.g. see Rosen, Baustad and Edwards, Forthcoming 2017). At an institutional level, an administrative rearrangement in the Social Science Research Unit (Institute of Education) at UCL brought 'childhood' and 'gender' researchers, including Katherine Twamley, under one research stream. Twamley's work is concerned with 'everyday feminism' in the context of intimate and familial relations, which, while often involving 'children', has been centred until now on adult relations (e.g. see Twamley 2012; O'Brien and Twamley forthcoming). Following the merger of the Institute of 
Education and UCL, there arose the opportunity to collaborate with colleagues from UCL Gender and Sexuality Studies, and by this means Ann Varley also became involved. This fortuitous set of events gave us an opportunity to unpack the possibilities and challenges of speaking across the disciplinary and political fields of gender and childhood, focusing particularly on feminism and the politics of childhood. ${ }^{1}$

In framing the symposium, we grappled with the challenge of simultaneously acknowledging the risks of reification involved in bringing women and children together as a topic of investigation, and the recognition that the everyday lives of women and children are deeply entangled. Children, to varying degrees, are positioned as primarily dependent, and women take the greatest responsibility for their care, in families, education, formal care settings, 'global care chains' (Hochschild 2000) and so on. Women and children have often been elided (i.e. women portrayed as child-like) or linked ideologically (Burman, 2008), such that womanhood is seen to be both made, and made worthwhile, through bearing and raising children (Phipps, 2014; Donner 2012). In India, for example, a woman is referred to as a 'girl' until she bears a child, when the title 'woman' is granted (Twamley 2014).

Both feminists and childhood scholars have questioned and, at times, fought against this elision, but in doing so tensions have arisen. For example, feminist efforts to achieve publicly-funded childcare - thereby questioning the natural place of women as at home carers - have been critiqued by some childhood theorists for largely reducing children to objects of social reproduction and ignoring the ways that children's participation in care-giving may intersect with women's (Mayall, 2002). Yet in contemporary Anglophone societies models of 'intensive parenting' are increasingly normalised, escalating the responsibilisation of parents in harmful ways, with mothers, in particular, held to account for children's "outcomes" (Fox, 2006; Gillies, 2014). A related feature of this highly individualistic model of parenting is the characterisation of children as vulnerable, needing to be supervised, protected and catered to at all possible times. This both belittles children and puts intense pressure on mothers, who report experiencing 'anxiety' 'guilt' and 'paranoia' (Furedi 2008).

Another tension relates to concerns about the disproportionate impacts of poverty on children. For example, in the UK, Ridge $(2009 ; 2013)$ has examined how cuts made to programmes and services for children under the mantle of austerity have had both material and social impacts on the lives of low-income children, including stigma and social isolation.

\footnotetext{
${ }^{1}$ I.e. where the focus is on gender and/or generation as a social relation of oppression.
} 
The focus on child poverty has been important in disaggregating children within economic measures, highlighting that poverty does not affect all family members in the same way or to the same degree. However, the international policy focus on child poverty can reproduce longstanding ideas about the 'deserving' poor (i.e. children) and shift attention away from mothers' poverty (Stasiulus, 2002). Concerns have also been raised that a focus on children's rights can have the effect of side-lining women's efforts at political articulations and achieving citizenship rights (Dobrowolsky and Jenson, 2004). Perhaps, as Burman and Stacey (2010) contend, a (liberal) rights-based framework creates competition between women and children.

These tensions attest to Thorne's (1987: 104) observation that women's emancipation has been framed as 'necessarily gained at the expense of children'. Some childhood theorists have described feminism as an 'adultist' enterprise, rendering children largely absent from the socio-political world and from scholarly consideration (Mayall 2002). In contrast, a number of feminists have contended that by premising adult-child power relations, the sociology of childhood neglects the salience of gender relations for both children and adults (Burman 2008). Each field has been criticised for neglecting respectively gender and childhood in their analysis or for portraying women's and children's interests as inherently adversarial (Burman 2008; Helleiner 1999).

Concerns have been raised that this conceptual antagonism reduces the complexity of adultchild relations - which can include joy, love, and reciprocal care - solely to that of work and burden (Riley 1987) in both academic scholarship and popular discourse. Twamley's research (2015), for example, with heterosexual parent couples showed that parents worry that goals for an egalitarian relationship, at least one where parents divide paid and unpaid work 'evenly', can paradoxically mean that the caring of children is reduced to a 'burden' to be off-loaded from one parent to another.

Until now, however, there has been limited attention to the ways feminists and those concerned with the subordination and oppression of children might speak to each other about these perceived antagonisms. Seminal texts identified both affinities and differences (Alanen 1994; Oakley 1994) and the necessity of conceptualising relations between women and children in order to analyse and address injustices for both groups (Thorne 1987). More recently, there has been growing attention to bringing feminist perspectives to the study of children and childhood (see Burman [2008] and special issues of the Australian Feminist 
Studies [Baird 2008] and Feminist Theory [Burman and Stacey 2010]). This work has focused primarily on girlhood and the use of the child as a trope in policy and popular culture, as well as interrogating which children, which women, and which feminisms are invoked in conceptualisations of childhood and gender. Arguably, less consideration has been given to the ways that feminism can learn from Childhood Studies, including the insights from recent scholarship in the majority world which prompts reconsideration of 'work' and 'care' in the lives of children and adults, and the ways these intersect (e.g. Abebe 2007; Tisdall and Punch 2012), as well as children's active involvement in socio-political movements (Liebel, 2003). Balagopalan (2010) makes this point clearly in relation to Indian feminist activists' seemingly intractable attachment to schooling as a panacea for the oppression of girls, despite the incursion of surveillance and neo-colonial discourses that such schooling brings to the lives of marginalised children. Our symposium and on-going project seek to address such perceived commonalities and antagonisms.

\section{The symposium}

To maximise the opportunity for debate and discussion, we kept the number of attendees to just 30, and selected 12 working papers for pre-circulation one month before the symposium. The papers were selected based on submitted abstracts, evaluated for relevance to the project themes, rigour, and innovation. We will also held an application procedure for non-presenting participants, outlining relevant academic and/or community-based experience. Presenters were asked to address the following thematic questions:

- How do we ensure the well-being of children and women, particularly in contexts where their interests may (appear to) be in conflict?

- How might a conversation between feminism and the politics of childhood reconcile these tensions?

- Are women's and children's interests necessarily opposed or inevitably linked?

- What are the consequences of denaturalizing motherhood and childhood for women and children?

- How do we conceptualise women and children's involvement in creating a gendered and generationed social order? 
- What are the implications of theorising women and children together?

- Does discussing women and children together reify their relationship?

- Where do men, the state, and society fit?

- To what extent does this reinforce compulsory heterosexuality?

During the symposium, authors were asked to provide a brief oral summary and this was followed by 25 minutes of discussion. This format required a large amount of reading for presenters and participants; however, it also allowed for more in-depth engagement with the papers than normally possible in standard conference formats. We created a website ${ }^{2}$ with video interviews, blogs and presentation summaries to disseminate the discussions, and are currently editing an anthology on the same themes (Rosen and Twamley, Forthcoming).

Symposium participants came from sociology, anthropology, social policy, geography, development, and psychology and some also had non-academic or multi-disciplinary affiliations. They drew on work from diverse locations, including Canada, India, Indonesia, Nigeria, and the UK. The diverse disciplinary and spatial contexts of the participants led to rich discussions as participants placed varying emphases on workshop questions and highlighted distinct problematics emerging from these different contexts. One such case was highlighted by the only paper submitted on behalf of a community-based organisation, CREA. ${ }^{3}$ Geetanjali Misra highlighted the conflicting rhetoric in India around the right to abortion, with women being increasingly 'blamed' for sex-selective abortions that are a consequence of and factor in the oppression of the girl-child (and women). Arguably, however, such discussions did not go far enough; there was a tendency to evoke a binary of North versus South, overlooking differences within each of these categories while also locating explanatory power primarily in the North - a problem highlighted previously in this journal (Punch and Tisdall 2012). Despite this persistent binary, intriguing glimpses of potential differences between places labelled 'North' or 'South' were at times overlooked but would have strengthened the discussions (e.g. see Camfield and Tafere 2011; Hilker 2014).

\section{Building a dialogue across academic and activist sectors}

\footnotetext{
${ }^{2}$ https://feminismandchildhood.wordpress.com/

${ }^{3}$ www.creaworld.org
} 
While we attracted participants from a wide range of disciplinary and geographical contexts, as mentioned above, only one of 12 papers selected was submitted on behalf of a communitybased organisation. ${ }^{4}$ This imbalance demonstrates the challenges of university-community collaborations. Despite widely circulating the call for participants and extending personal invitations to relevant organisations and offering funded places, few members of community based organisations chose to participate. Although activists may well draw on and be engaged with similar debates, we surmise that our framing of the event emphasised our academic concerns and outputs in four ways.

First, despite our supposition that the workshop themes were highly relevant for communitybased organisations, the framing of the event emerged from debates within the academic literature and therefore may not have seemed immediately relevant and urgent. Second, in the context of tightening austerity, feminist groups - especially those of minoritised women - are facing challenges to their own funding sources at the same time as intensification of the issues facing those whom they work with and for (Vacchelli, Kathrecha and Gyte, 2015), leaving less time to engage with events such as this. Third, our call for participants followed academic conventions of literature citation, which may have been off-putting for those unfamiliar with (and without access to) these texts. Finally, the format of the symposium, although participatory, largely followed academic conference conventions, was located at our university, and with the potential extra stress of pre-circulated papers for those less experienced in writing and peer review.

It is worth noting, however, that many of those present at the symposium would reject the bifurcation of activist and academic activity, pointing to the importance of change-oriented and collaborative knowledge production for social transformation as well as their own participation in social movements, beyond academic roles and responsibilities. That participants largely presented themselves via their academic affiliations, however, is indicative of the tenor of the workshop.

These points highlight some of the challenges facing academics concerned with taking up Burawoy's (2005) call for social science scholarship which extends beyond the academe to the 'public' and 'counter-public' in order to 'instigate debate' and even 'strike up a dialogic relation'. On the one hand, such engagements can be argued for in contexts like the UK

\footnotetext{
${ }^{4}$ One further paper was submitted from community / activist organisations, but was not selected due to lack of relevance. Representatives from three activist organisations were also invited to attend, but only one was able to come.
} 
where 'impact' is increasingly required to justify social science research. On the other hand, the pressures of academic publishing - such as the increasing quantification via citation statistics and audit culture - place constraints on the extent to which we can innovate, or even see the potential to do so (Boden and Epstein 2011; Burrows 2012).

Reflecting on the workshop format highlights that the extent to which the social sciences are able to become dialogic, in Burawoy's sense, is in part influenced by the forms in which scholarship is made available and amenable to intervention and interaction. This has implications for dialogue, but also raises questions about agenda setting. To this end, we are working on an anthology of papers, and - in addition to more traditional chapter formats - we have invited activist and advocacy groups to write short commentaries, photo essays, or other inputs considering the ways in which their campaigning and organising efforts speak back to or are inspired by the arguments made in the chapters, as well as the ways that more traditional academic work can learn from social movements. We hope contributions less confined by academic formats will be more welcoming to those from outside of the academe and, in this way, both extend and 'give flesh' to research concepts and data, and help to continue the dialogue. By asking for activist contributors to draw on their own communitybased experiences to answer the central questions of the project, and to feed into a review process of other chapter contributions, we are attempting to move beyond mere tokenism in this endeavour.

\section{Concluding remarks}

The key aim of the symposium was to facilitate a conversation between feminism and the politics of childhood, focusing on the ways that these fields do and can attend to those positioned as women and as children. Whether this was achieved or not rests largely on whom you speak with. Participants who identified themselves primarily as feminists pointed to the limited focus on gender in the discussions, while childhood scholars lamented the absence of a generational focus. Some, who saw themselves as both feminist and childhood scholars, were disturbed by the positioning of themselves and others in one 'camp' or the other. We contend that discussions fluctuated across the course of the two days, reflective of the variety of papers and often linked to the initial lines of discussion proposed in response to each paper, but that such perceptions indicate that participants were pushed outside of their comfort zone and thus 'noticed more' the effort in thinking through gender or generation 
(whichever they were least familiar with). No distinct conclusions were reached other than that further thought and debate was needed. We will take this challenge forward in a future viewpoint article and our forthcoming anthology.

Acknowledgements: We are grateful to UCL Grand Challenges for funding the symposium, to Ann Varley for her role in co-facilitating the symposium, and to all the presenters and participants who contributed to discussions.

\section{References}

Abebe, T. (2007) Changing livelihoods, changing childhoods: Patterns of children's work in rural southern Ethiopia, Children's Geographies, 5 (1-2): 77-93.

Aitken SC (2004) Editorial: from dismissals and disciplinary inclusions; from block politics to panic rooms, Children's Geographies, 2:2, 171-175,

Alanen, L. (1994). 'Gender and Generation: Feminism and the 'Child Question". In J. Qvortrup, M. Bardy, G. Sgritta and H Wintersberger (eds) Childhood Matters Aldershot: Avebury, p27-42

Baird, B. (Ed). (2008). The Child [Special Issue]. Australian Feminist Studies, 23(57).

Balagopalan, S. (2010). 'Rationalizing seclusion: A preliminary analysis of a residential schooling scheme for poor girls in India'. Feminist Theory, 11 (3), 295-308.

Boden R and D Epstein (2011) A flat earth society? Imagining academic freedom The Sociological Review 59(3)

Burman, E. (2008). 'Beyond 'women vs. children' or 'womenandchildren': Engendering childhood and reformulating motherhood'. The International Journal of Children's Rights, 16 (2), 177-194.

Burman, E. and Stacey, J. (2010). 'The child and childhood in feminist theory'. Feminist Theory, 11 (3), 227-240.

Burman, E. and Stacey, J. (Eds) (2010). 'The child and childhood' [Special issue]. Feminist Theory, 11(3).

Burrows, R. (2012). "Living with the h-index? Metric assemblages in the contemporary academy." The Sociological Review 60(2): 355-372. 
Camfield, L. and Tafere, Y. (2011) Community understandings of childhood transitions in Ethiopia: different for girls?, Children's Geographies, 9(2): 247-262.

Dobrowolsky, A. and Jenson, J. (2004). 'Shifting representation of citizenship: Canadian politics of 'women' and 'children'. Social Politics, 11 (2), 154-180.

Donner, H (2008) Domestic Goddesses: Maternity, Globalization and Middle-class Identity in Contemporary India Aldershot: Ashgate

Firestone, S. (1971). The Dialectic of Sex : The Case for Feminist Revolution. London: Jonathan Cape.

Fox, B. (2006). 'Motherhood as a class act: The many ways in which "intensive mothering" is entangled with social class'. In K. Bezanson and M. Luxton (Eds), Social Reproduction: Feminist Political Economy Challenges Neo-liberalism (pp. 231-262). Montreal and Kingston: McGill-Queen's University Press.

Gillies, V. (2014). 'Troubling Families: Parenting and the Politics of Early Intervention'. In S. Wagg and J. Pilcher (Eds), Thatcher's Grandchildren? Politics and Childhood in the Twenty-first Century. Basingstoke: Palgrave Macmillan.

Helleiner, J. (1999). 'Toward a Feminist Anthropology of Childhood'. Atlantis, 24 (1), 27-38.

Hilker, L. (2014) Navigating adolescence and young adulthood in Rwanda during and after genocide: Intersections of ethnicity, gender and age, Children's Geographies, 12(3): 354-368.

Hochschild, A. R. (2000). 'Global Care Chains and Emotional Surplus Value'. In W. Hutton and A. Giddens (Eds), On The Edge: Living with Global Capitalism. London: Jonathan Cape.

Liebel, M. (2003). 'Working children as social subjects: The contribution of working children's organizations to social transformations'. Childhood, 10 (3), 265-285.

Mayall, B. (2002). Towards a Sociology for Childhood: Thinking from children's lives. Buckingham: Open University Press.

Molyneux, M. (2006). 'Mothers at the service of the new poverty agenda: Progresa/Oportunidades Mexico's conditional transfer programme'. Social Policy \& Administration, 40 (4), 425-449. 
Newberry, J. (2014). 'Women Against Children: Early Childhood Education and the Domestic Community in Post-Suharto Indonesia'. TRaNS: Trans -Regional and National Studies of Southeast Asia, 2, 271-291.

Oakley, A. (1994). 'Women and Children First and Last: Parallels and Differences Between Children's and Women's Studies'. In B. Mayall (Ed.), Children's Childhoods: Observed and Experienced (pp. 13-32). London: Falmer Press.

O'Brien M and Twamley K (Forthcoming 2016) Fathers taking leave alone in the UK - a gift exchange between mother and father? in O'Brien M and K Wall (Eds) Fathers on Leave Alone and Gender Equality: An International Comparative Perspective, London: Springer

Phipps, A. (2014) The Politics of the Body. Cambridge: Polity Press.

Punch, S. and Tisdall, K. (eds) (2012) Exploring children and young people's relationships across majority and minority worlds, Special Issue of Children's Geographies, 10(3).

Ridge T. 2009. Living with Poverty: A Review of the Literature on Children's and Families' Experiences of Poverty. Research Report No 594. Department for Work and Pensions, HMSO: Norwich.

Ridge, T. (2013), 'We are All in This Together'? The Hidden Costs of Poverty, Recession and Austerity Policies on Britain's Poorest Children. Children \& Society, 27: 406-417.

Riley, D. (1987). 'The Serious Burdens of Love?" Some Questions on Childcare-Feminism and Socialism'. In A. Phillips (Ed.), Feminism and Equality (pp. 176- 198). Oxford: Blackwell.

Rosen, R., Baustad, S. and Edwards, M. (Forthcoming 2017). 'The crisis of social reproduction under global capitalism: Working class women and children in the struggle for universal childcare'. In R. Langford, S. Prentice and P. Albanese (Eds), Caring for Children: Social Movements and Public Policy in Canada.

Rosen, R., and Twamley K (eds) (Forthcoming) Feminism and the Politics of Childhood: Friends or Foes? London: University College London Press.

Ruddick, S. (2007). 'At the Horizons of the Subject: Neo-liberalism, neo-conservatism and the rights of the child Part One: From 'knowing' fetus to 'confused' child'. Gender, Place \& Culture, 14 (5), 513-527. 
Thorne, B. (1987). 'Re-visioning women and social change: Where are the children?'. Gender and Society, 1 (1), 85-109.

Tisdall, K. and Punch, S. (2012) Not so 'new'? Looking critically at childhood studies, Children's Geographies, 10(3): 249-264.

Twamley K (2012) Gender relations among Indian couples in the UK and India: Ideals of equality and realities of inequality. Sociological Research Online 17(4) 5

Twamley, K (2014) Love, Marriage and Intimacy Amongst Gujarati Indians: A Suitable Match Basingstoke: Palgrave Macmillan

Twamley K (2015) What's love got to do with it?: Exploring the narratives of couples who share leave in the first year after the birth of a child British Sociological Association Annual Conference, April 2015, Glasgow

Vacchelli, E., Kathrecha, P. and Gyte, N. (2015). 'Is it really just the cuts? neo-liberal tales from the women's voluntary and community sector in London'. Feminist Review, 109 (1), 180-189. 